\title{
Polymorphisms in Eruption Sequence of Permanent Teeth in American Children
}

\author{
B. HOLLY SMITH AND STANLEY M. GARN \\ Museum of Anthropology (B.H.S.) and Center for Human Growth and \\ Development (S.M.G.), The University of Michigan, Ann Arbor, \\ Michigan, 48109
}

\begin{abstract}
KEY WORDS Human dentition, Tooth eruption sequence, Tooth emergence
\end{abstract}

\begin{abstract}
This study provides basic descriptive data on the frequency of pairwise eruption sequences ascertained in cross-sectional examination of 6,000 black and white American children in the Ten State Nutritional Survey of 1968-1970. All sex and race groups share a distinct pattern of sequence polymorphisms in terms of location, number, and level. Teeth in eruption phase I (M1, I1, I2) rarely reverse in sequence with those in phase II (C, P1, P2, and M2). Five sequences have variants that appear at $\geqslant 20 \%$ in all groups, with $\mathrm{M}_{1} \mathrm{I}_{1}$ vs. $\mathrm{I}_{1} \mathrm{M}_{1}$ approaching maximum polymorphic values of $50 \% / 50 \%$. The traditional notation for eruption sequences can be modified to reflect these important variants, giving the sequence M1 I1 I2 [P1 C P2] M2 for the maxilla and [M1 I1] I2 [C P1] [P2 M2] for the mandible. The location of major polymorphisms is explicable by close timing of teeth within phase I and, separately, teeth within phase II eruption. However, strong integration of development of physically adjacent teeth apparently acts to reduce substantially the number of sequence reversals. The Ten State Survey data provide a sound descriptive basis for two populations, yet precise comparative data are available for few other human groups or primate species.
\end{abstract}

The sequence of eruption of permanent teeth is of concern in orthodontics, pedodon tics, comparative odontology, and evolution of the dentition. We know the order of means of tooth emergence age in many human populations (Steggerda and Hill, 1942; Hurme, 1949; Dahlberg and Menegaz-Bock, 1958; see Jaswal, 1983, for recent review), but surprisingly few data exist on actual sequence of tooth eruption within individuals.

A sequence constructed from mean eruption ages usually indicates the modal sequence in the population (see Knott and Meredith, 1966; Savara and Steen, 1978; this study). However, this becomes inadequate for evaluation of an individual, whether a single child or a single fossil, since it gives no information on frequency or significance of deviations. Population comparisons of sequences based on means can be misleading. One group may show $M_{1} I_{1}$ and another $I_{1} M_{1}$ in mean order. This could mean that $M_{1} I_{1}$ oc- curs at $100 \%$ in the first and $0 \%$ in the second-a major population difference. Alternatively, $\mathrm{M}_{1} \mathrm{I}_{1}$ might occur at $52 \%$ in the first and $48 \%$ in the second-a comparatively insignificant difference. Expressing eruption sequence as the order of means reduces all frequencies to zero or one, obscuring the magnitude of similarity or difference. In addition, frequencies of actual sequences in individuals cannot be predicted simply from means and standard deviations of tooth emergence in populations (Adler and Polczer, 1964; this study). Lastly, sequence variability is of interest because it is not uncommon. The term "polymorphic" is useful to emphasize both the high level of particular variants and the likelihood of an ultimate genetic basis, although this basis is probably complex (see Garn et al., 1962, 1963).

Received February 2, 1987; accepted May 4, 1987 
The present study provides new information on the frequency of pairwise eruption sequences within individuals as ascertained from cross-sectional examination of 6,000 black and white American children. These comprehensive basic data provide information for clinicians, point out areas of interest for further population comparisons, and provide a basis for evolutionary comparison of fossil and recent humans.

\section{BACKGROUND}

Schultz (1940) recognized individual variability in eruption sequence and used brackets to indicate variable positions, giving the human sequence as [M1 I1] I2 [P1 C P2] M2. Subsequently Adler and Godeny (1952) and Clements et al. (1953) described individual variation in a number of sequences, extending variants to include M2. Lo and Moyers (1953) and later Anderson and Popovich (1981) investigated the relationship of eruption sequence to occlusion. Knott and Meredith (1966) and Savara and Steen (1978) investigated sequence and developmental timing. All these studies pertain to children of European ancestry. Data for a few sequences are available for a few other human populations: Koski and Garn (1957) on Pima Indians, Barrett et al. (1964) on Australian aborigines, and Debrot (1968) on children of Curaçao. Unfortunately, it is not easy to compare these different sources. Important differences in basic methods of tabulating sequence data render many (perhaps most) studies incomparable. The methods of Adler and Godeny (1952), Clements et al. (1953), Knott and Meredith (1966), Debrot (1968), and Savara and Steen (1978) are each unique. Further, cross-sectional studies vary in age of children studied, and failure to include the full age range of tooth eruption can skew eruption sequence frequencies (Adler 1963; Barrett et al., 1964). Differences in the treatment of ties in longitudinal eruption data make some studies incomparable (cf. Savara and Steen, 1978; Barrett et al., 1964).

Much of what we know about eruption sequence in individuals stems from evolutionary studies. Juvenile fossil hominids were in several cases claimed to show the apelike sequences of eruption $\mathrm{M}_{2} \mathrm{P}_{2}$ or $\mathrm{M}_{2} \mathrm{C}$ (Weidenreich, 1937; Dart, 1948; Senyurek, 1955). A series of papers by Garn, Koski, and Lewis demonstrated the noncomparability of bony alveolar to gingival eruption sequences, and the difference in both of these from calcification sequence, casting doubt on identification of many sequences in fossils (Garn et al., 1956, 1957; Garn and Koski, 1957; Koski and Garn, 1957; Garn and Lewis, 1963). Phylogenetic studies received a second blow with the discovery of variability in living humans in the very sequences said to have particular phylogenetic significance. Garn and associates showed that $\mathrm{M}_{2} \mathrm{P}_{2}$ was by no means uncommon in living humans, and this remains the best-known "sequence polymorphism" to date. Phylogenetic studies of hominid tooth eruption sequence virtually ceased after this (excepting Wallace, 1977; and Dean, 1985), although the interest in evolutionary change did lead to study of human prenatal developmental sequences (Garn and Burdi, 1971; Burdi et al., 1975) and to study of sequence of maxillary vs. mandibular tooth eruption (Israel et al., 1967).

Although we know the general outline of individual eruption sequence variability, comprehensive basic data are lacking and much misinformation appears in the literature. The present study provides simply organized basic data for sequences involving the permanent teeth I1 through M2 for male, female, black, and white children. Patterns of eruption sequence polymorphisms are considered in terms of location, number, and level. Population and sex differences are assessed on comparable data sets, each cover. ing the full range of age of tooth eruption. The significance of findings is considered for studies of occlusion, timing and integration of dental development, and comparative odontology. Lastly, we return to the question of the profitability of phylogenetic study of eruption sequence.

\section{MATERIALS AND METHODS}

A truly large initial pool of subjects is needed for unbiased estimate of eruption sequences of all permanent teeth in cross-sectional study. The Ten State Nutritional Survey of 1968-1970 contains information on teeth erupted and unerupted for approximately 12,000 black and white children between the ages of 1.0 and 17.5 years, easily encompassing the 1st and 99th percentiles for eruption of I1 through M2 in both arches (Garn et al., 1973a,b). Of these children, 5,867 had at least one but less than 14 permanent teeth erupted, thus contributing information on sequence of eruption. Appearance of any part of the tooth through the gingiva is the criterion of eruption in all cases, so strictly speaking these are gingival emergence se- 
quences. However, eruption sequence remains the more general term, more applicable to general discussion.

These cross-sectional, presence-absence data are used to construct sequences by counting "tooth A erupted, tooth $B$ unerupted" as the eruption sequence AB. Children showing $A B$ and those showing its inverse, $\mathrm{BA}$, represent the total number giving information on that pair of teeth. Frequencies are tabulated for each sequence and its inverse (summing to 1.0) for all possible pairs of teeth within each arch, confining data to left-side teeth throughout. Results are presented in matrix form, an approach used by Garn et al. (1972a) to summarize sequence of appearance of ossification centers of the hand. Results are separated by dental arch, sex, and population, giving a total of eight matrices in all (Fig. 1 A,B). Sequences of maxillary vs. mandibular teeth are separately presented in a conventional table. Here eruption of isomeres (the opponents $I_{1} I^{1}$, etc.) is of greatest interest, yielding only seven sequence comparisons for each race/sex group.

Sample size for particular pairs of teeth ranges from 104 to 1,611 within a race/sex/ jaw matrix and from 67 to 314 for opponent sequences. The smaller samples generally indicate eruption events that are more closely spaced in time. Given these adequate sample sizes, nearly all frequencies reported at $\geqslant 5 \%$ are significantly different from zero at $P<.05$. It is not at issue here whether very low frequencies are significant, and thus likewise not at issue whether or not certain extreme variants actually exist. Sequences occurring at less than $5 \%$ are considered rare for the purposes of the present study and the term "polymorphic" is reserved for sequences present at $\geqslant 5 \%$. It is useful to keep a general idea of confidence limits in mind as matrices are scanned. Confidence intervals of $95 \%$ range from \pm .025 for $\mathrm{N}=1500$ to \pm .05 for $\mathrm{N}=350$ and \pm .10 for $\mathrm{N}=100$.

The benefit of large sample size is balanced by some costs, and a few warnings are necessary: (1) Agenesis: For Ten State children, no data exist to distinguish agenesis from unerupted teeth. Since the third molar is not a part of this study, eruption sequences affected are primarily those involving $\mathrm{P}_{2}$ or $\mathrm{I}^{2}$. Agenesis of these latter teeth is relatively rare even in European-derived groups, ca. two to three in 100 for $\mathrm{P}_{2}$ and one to two in 100 for $\mathrm{I}^{2}$ (Grahnen, 1956; Garn et al., 1962; LeBot and Salmon, 1977). Slightly lower fig- ures would be expected for a study limited to a single side of the dentition such as the present one (taking .75 the "either-side" frequency, see Grahnen, 1956). Agenesis of other teeth is reportedly on the order of one in a 1,000-less for M1 (Grahnen, 1956). Thus, frequency of sequences involving any tooth erupting before $\mathrm{P}_{2}$ or $\mathrm{I}^{2}$ is probably inflated by $1-2 \%$. No attempt has been made to correct the data. Agenesis is a problem in all cross-sectional studies of tooth eruption, also complicating the definition and estimation of median age of eruption for affected teeth. (2) Error: Four extremely deviant sequences (M2M1, M2I1, P2M1, and P2I1) are reported at an average frequency of 2.7 in 1,000 in Ten State data as a whole. Recording errors should be responsible for some of these, al. though local pathologies must contribute (see Johnsen, 1977). We have minimized the distracting effect of errors and extremely rare variants by rounding all frequencies to the nearest whole percent in matrices. (3) Independence: These cross-sectional data improve conditions of independence compared to longitudinal studies where all sequences are based on the same pool of subjects. Ten State data are in comparison partially independent. Children contributing to sequences involving $\mathrm{M}_{1}$ and $\mathrm{I}_{1}$ (ca. age $4.5-7.5$ years) are entirely different from those contributing to $M_{2}$ and $P_{2}$ (ca. age 9-14). However, data for a single child may appear for several sequences: i.e., a child with an early emerging M2 might be counted as M2P1, M2C, and M2P2. Because of this, estimates of frequencies of related sequences are not independent.

\section{RESULTS}

A complete emergence sequence can be assembled from the most common results for individual pairs of teeth. In Ten State children this is M1 I1 I2 P1 C P2 M2 in the maxilla and M1 I1 I2 C P1 P2 M2 in the mandible. Any sequence in partial disagreement with this is referred to as a "variant" throughout. Modes of individual sequences concur with sequences based on order of median emergence ages in the groups published elsewhere (Garn et al., 1973b). Matrices in Figure 1 list teeth in the above order. It should be noted that white males show some exceptions to the typical sequence found in other groups. White males show a later emergence of the canine in the maxilla and a preponderance of the I1M1 sequence in the mandible. 


\section{A. WHITE}

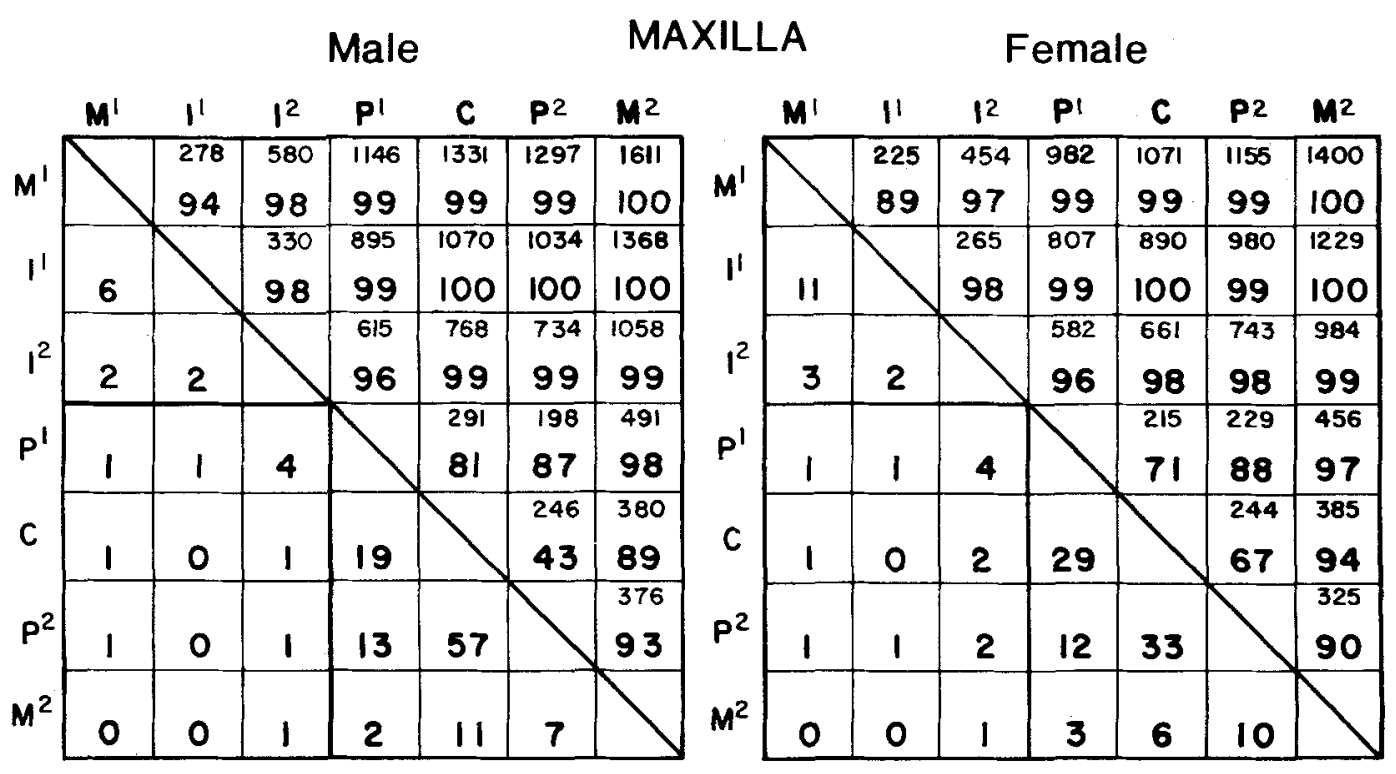

\section{MANDIBLE}

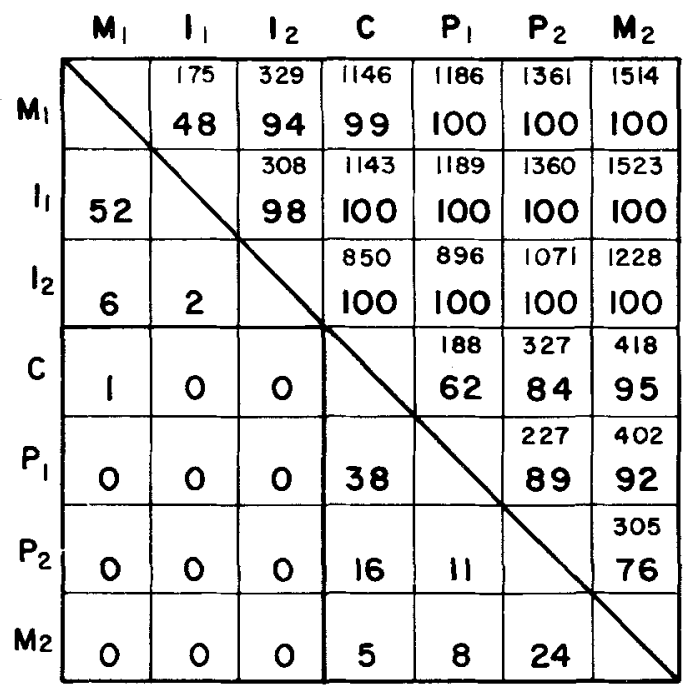

Fig. 1. Percent of children showing each two-tooth emergence sequence. Eight matrices separate results by sex (males left; females right), and dental arch (maxilla top; mandible, bottom) within each population (whites A; blacks B). For each matrix, teeth listed vertically are present (erupted); those listed horizontally are absent (unerupted). Boxes within each matrix contain percent of cases with indicated sequence (to nearest whole number). Note that percents in corresponding boxes across the diagonal sum to 100 , representing occurrence of a sequence and its inverse (e.g., P2M2 vs. M2P2). Total N for each tooth pair appears only once, in smaller numer-

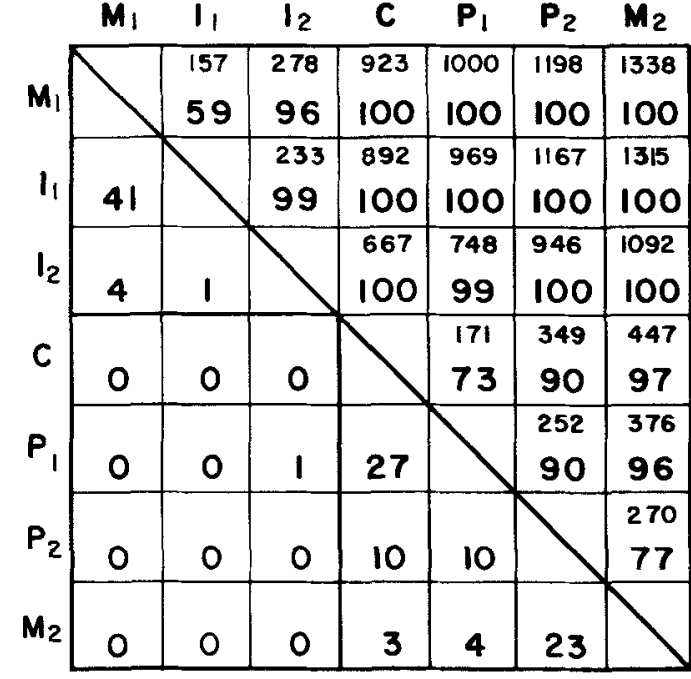

als above the diagonal. Example for white male maxilla: of 278 children allowing discrimination of order, $94 \%$ are $\mathrm{M}^{1} \mathrm{I}^{1}$ and $6 \%$ are $\mathrm{I}^{1} \mathrm{M}^{1}$. Frequencies for rarer sequences generally appear below the diagonal. These are below $50 \%$ if teeth are listed in best order for the data (note two exceptions for white males). The region below the diagonal can be quickly scanned for pattern; that above can be searched for $\mathrm{N}$. Twelve adjacent sequences are set off in each matrix by a heavier line; all these are rare. Total number of subjects in matrices: 1,857 white males, 1,643 white females, 1,154 black males, and 1,213 black females. 


\section{B. BLACK}

Male

MAXILLA

Female
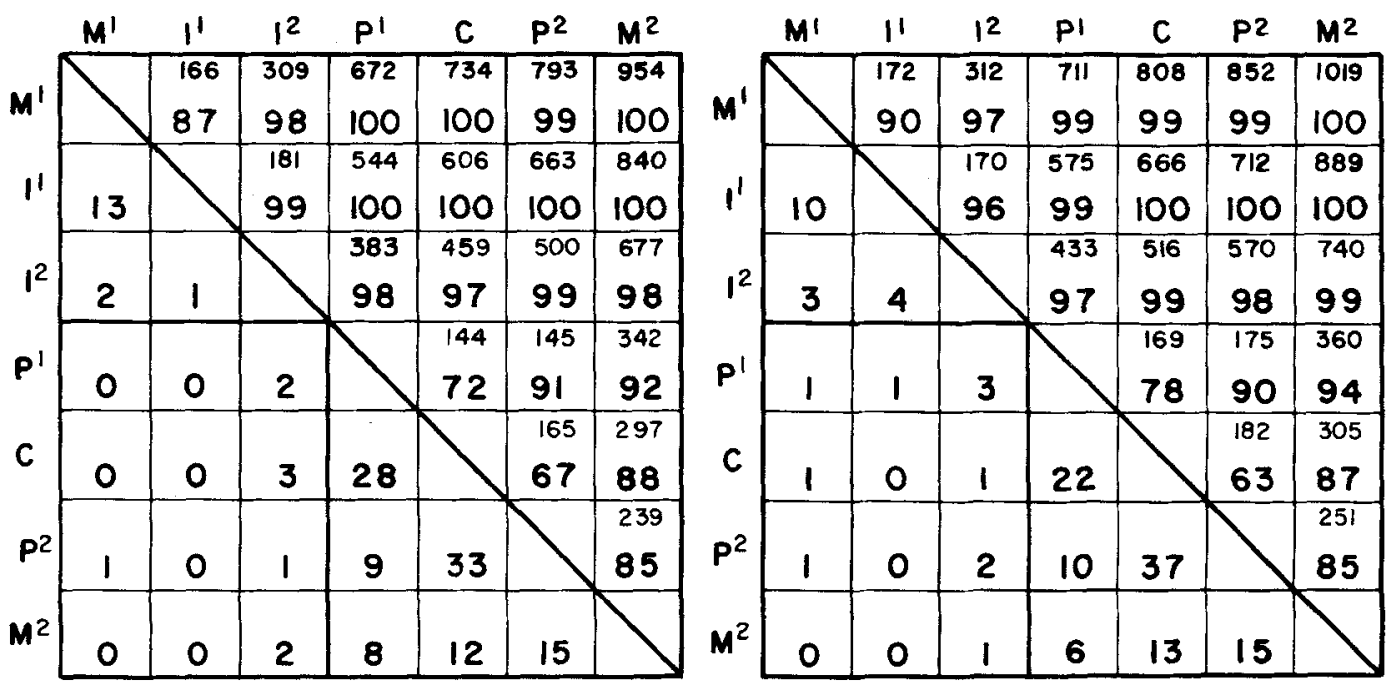

\section{MANDIBLE}

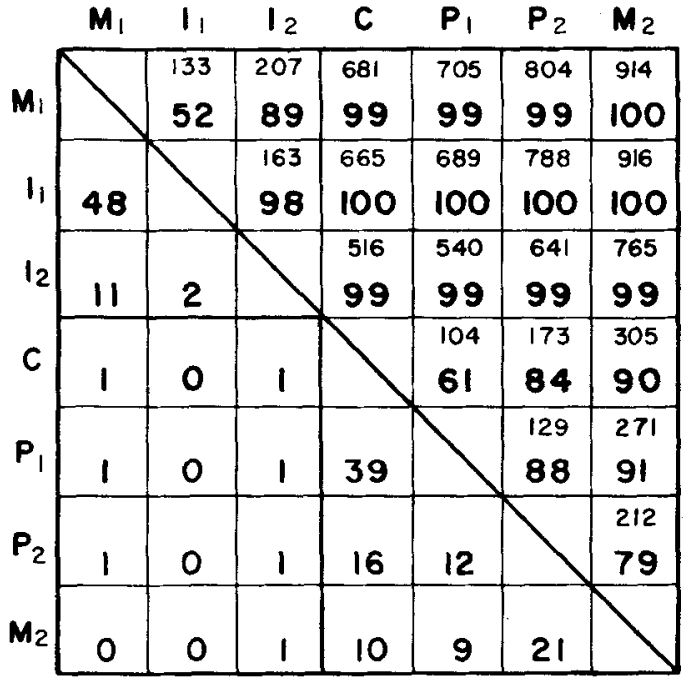

Location of polymorphisms

Variants in sequence appear in particular pairs of teeth and not in others. To bring some order to the discussion, variants will be discussed by phase of tooth eruption, and more briefly, by jaw and by tooth. Here we refer to the general pattern shown by all race/sex groups in Figure $1 \mathrm{~A}$ and $\mathrm{B}$.

It is well known that human children show

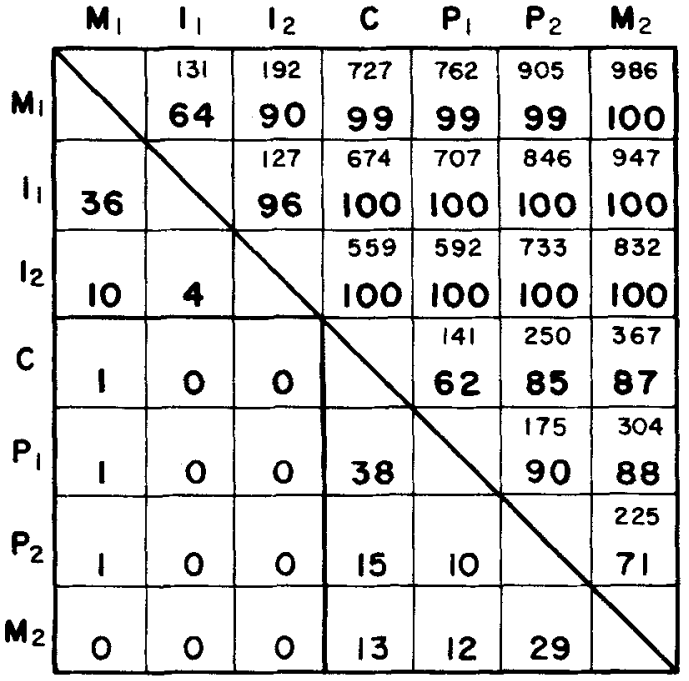

two major phases of permanent tooth eruption separated by a pause (Schour and Massler, 1941; and others). The first phase consists of M1, I1, and I2, and the second of C, P1, P2, and M2 (M3 would be considered a third phase). The most striking feature of the eight matrices is that teeth in phase I rarely reverse with those of phase II. This is certainly not the first such observation (see Ad- 
ler and Godeny, 1952), but Figure 1 is probably the first comprehensive demonstration. A block of 12 boxes in the left corner of each matrix has been outlined; these 12 sequences require emergence of teeth in phase II before those in phase I. Values between 0 and $1 \%$ occupy this space (note that frequencies for teeth erupting before $\mathrm{I}^{2}$ are inflated by $\mathrm{I}^{2}$ agenesis). The dentition is essentially divided into two separate polymorphic "regions" (represented by two remaining triangles below each matrix diagonal): one internal to phase I teeth and a second internal to phase II teeth.

For phase I (M1, I1, I2), only one variant sequence exists at an important level: I1M1 in the mandible. This is the only sequence to approach a 50/50 frequency in these data for most groups. It is not even possible to state which tooth emerges first in males given $95 \%$ confidence limits for the sequence $\mathrm{I}_{1} \mathrm{M}_{1}$ of .52 \pm .07 for whites and $.48 \pm .08$ for blacks. The $\overrightarrow{\mathrm{M}}_{1}$ polymorphism apparently extends to $\mathrm{I}_{2}$; $\mathrm{I}_{2} \mathrm{M}_{1}$ is recorded as high as $5 \%$ in whites and $10 \%$ in blacks. In the maxilla, however, $\mathrm{M}^{1}$ is more clearly the first tooth to erupt: $\mathrm{I}^{1} \mathrm{M}^{1}$ occurs in only $6-13 \%$ of children, and $\mathrm{I}^{2} \mathrm{M}^{1}$ is rare $(2-3 \%)$. The remaining phase I sequence is $\mathrm{I1I} 2$; reversal of this order is rare in both upper and lower arches.

Eruption phase II (C, P1, P2, M2) is far more complex in internal sequence polymorphism. All possible combinations can occur at polymorphic levels and in no case does a variant drop to $1 \%$ as found for some phase I sequences. The terms "one-rank, two-rank, and three-rank" displacements (Nissen and Riesen, 1964) are useful to distinguish minor to major variations on the modal eruption sequence. One-rank displacements (boxes immediately below matrix diagonals in Fig. 1) occur at highest frequencies, 20-40\%. Two exceptions are found: $\mathrm{P}_{1}$ and $\mathrm{P}_{2}$ show a definite tendency to maintain their order, reversing at only $11 \%$ (range: $10-12 \%$ ), and $\mathrm{P}^{2}$ and $\mathrm{M}^{2}$ reverse at only $12 \%(6-15 \%)$. Sequences involving two-rank displacements center around $11 \%(4-15 \%)$. Lastly, the two sequences necessitating three-rank displacement are expectably rarest: $\mathrm{M}_{2} \mathrm{C}$ at ca. $8 \%$ (3-13\%), and $\mathrm{M}^{2} \mathrm{P}^{1}$ at ca. 5\% (2-8\%).

Reviewing polymorphisms by jaw, the maxilla appears to be less variable. Two common variants of mandibular teeth are rare in the maxilla: I1M1 and M2P2. In fact, modal sequences and variants differ substantially in the two arches in humans. Only two vari- ants appear at high levels in the maxilla, both of these involving the canine: $\mathrm{CP}^{1}$ and $\mathrm{P}^{2} \mathrm{C}$. In contrast, the mandible has at least three high-level variants that involve six teeth: $\mathrm{I}_{1} \mathrm{M}_{1}, \mathrm{P}_{1} \mathrm{C}$, and $\mathrm{M}_{2} \mathrm{P}_{2}$ (Table 1).

If matrices are reviewed for the single tooth that contributes most to sequence variation, the answer is clear. The largest number of high-level variants would be lost if the canine were removed from the matrices, an effect that holds for both maxilla and mandible.

\section{Level of polymorphisms}

Another striking feature of the eight matrices is the high magnitude of sequence polymorphisms. Although some 15 maxillary and mandibular sequences might be regarded as variable, five stand out as major polymorphisms in all sex/race groups (see Table 1). These five "variant" sequences occur approximately from 20 to $50 \%$ whereas the level of polymorphism in remaining sequence drops to $10-15 \%$ or less. All five sequences are "one-rank" displacements (see above). Values in Table 1 point out how far we are from characterizing these populations by listing any one complete sequence. If we arbitrarily regard a significant polymorphism as one occurring at greater than $20 \%$, we could write the Ten State sequence as M1 I1 I2 [P1 C P2] M2 for the maxilla and [M1 I1] 2 [C P1] [P2 M2] for the mandible.

\section{Sex and population differences}

Multiple tests and partially independent data mean that race/sex comparisons must be approached with caution. We compare only polymorphic sequences, but even so the number of statistically significant differences is not high: six of 30 sex differences and 11 of 30 race differences (see Tables 2,3 ). Tables

TABLE 1. The five most common sequence variants and their frequency of occurrence in the four groups.

\begin{tabular}{|c|c|c|c|c|}
\hline \multirow{3}{*}{$\begin{array}{l}\text { Variant } \\
\text { sequence }\end{array}$} & \multicolumn{4}{|c|}{ Percent occurrence } \\
\hline & \multicolumn{2}{|c|}{ Whites } & \multicolumn{2}{|c|}{ Blacks } \\
\hline & Males & Females & Males & Females \\
\hline \multicolumn{5}{|l|}{ Maxilla } \\
\hline P2C & 57 & 33 & 33 & 38 \\
\hline \multirow{2}{*}{\multicolumn{5}{|c|}{ Mandible }} \\
\hline & & & & \\
\hline I1M1 & 52 & 41 & 48 & 36 \\
\hline $\mathrm{P} 1 \mathrm{C}$ & 38 & 27 & 39 & 38 \\
\hline $\mathrm{M}^{2} 22^{1}$ & 24 & 23 & 21 & 29 \\
\hline
\end{tabular}

${ }^{1}$ Estimate may be inflated by agenesis of $\mathrm{P}_{2}$; sample sizes for all values available in Figure 1. 
are simplified by omitting P2P1. For the record, $\mathrm{P} 2 \mathrm{PI}$ is fairly stable at near $10 \%$ in all groups in both jaws and makes up eight of the nonsignificant comparisons. Remaining polymorphic sequences concern either canines or molars, allowing a more ordered discussion.

Results for population/sex comparisons require a brief explanation of prior expectations (organization of results has been determined by predictions). A clear prediction concerns the direction of results for sex differences. Males should have higher frequencies of sequences involving "canine late" (Adler and Godeny, 1952; Hurme, 1957) consistent with the dimorphic size (see Garn et al., 1967) and developmental timing (Moss and Moss-Salentijn, 1977) of these teeth. Phrased alternatively, males should lack "canine early" sequences. These whites exhibit strong sex differences in canine sequences (Table 2). Compared to females, white males show lower frequencies of the "canine early" sequences $\mathrm{CP}^{1}, \mathrm{CP}^{2}, \mathrm{CM}^{2}$, $\mathrm{CP}_{1}, \mathrm{CP}_{2}$, and $\mathrm{CM}_{2}$. Most are statistically significant, although the interdependence of these tests means that this has been shown once, rather than six separate times. Surprisingly, no coherent pattern of canine sequence dimorphism appears in the Ten State black sample. In fact, no sex difference in blacks reaches statistical significance. The only feature of sex difference common to both blacks and whites is a $10-12 \%$ excess of the variant $I_{1} M_{1}$ in males, although this is significant at only $P<.06$.

One a priori expectation might be stated for population differences. Work on mean age of tooth emergence has made it clear that European-derived populations are late compared to most peoples of the world (Steggerda and Hill, 1942; Dahlberg and Menegaz-Bock, 1958; Garn et al., 1972b; Mayhall et al., 1978; and others). Molar eruption is particularly late (Garn et al., 1973b), and we might expect to see a corresponding increase in "molar late" sequences in American whites compared to blacks. In Table 3 , whites tend to show higher frequencies of "molar late" sequences: $\mathrm{CM}^{2}, \mathrm{P}^{1} \mathrm{M}^{2}, \mathrm{P}^{2} \mathrm{M}^{2}, \mathrm{CM}_{2}, \mathrm{P}_{1} \mathrm{M}_{2}$, $P_{2} M_{2}$, and $I_{1} M_{1}\left(I_{2} M_{1}\right.$, not very common in any group, does not follow prediction). Of 18 tests, 14 show the predicted direction of results, and seven of these are statistically significant (tests of I1M1 are independent from other tests). Remaining population differences in male canines reflect again the high dimorphism found in whites but not blacks,

TABLE 2. Sex differences in frequencies of polymorphic sequences

\begin{tabular}{|c|c|c|c|c|c|c|c|}
\hline \multirow{3}{*}{$\begin{array}{l}\text { Dental } \\
\text { arch }\end{array}$} & \multicolumn{7}{|c|}{ Sex difference in percent (male minus female) } \\
\hline & \multicolumn{3}{|c|}{ Canine sequences $^{1}$} & \multicolumn{4}{|c|}{ Molar sequences } \\
\hline & CP1 & CP2 & CM2 & P1M2 & P2M2 & I1M1 & I2M1 \\
\hline \multicolumn{8}{|l|}{ Whites } \\
\hline Maxilla & $-9.6^{*}$ & $-23.7^{*}$ & $-5.6^{*}$ & 0.8 & 3.8 & -5.0 & - \\
\hline Mandible & $-11.4^{*}$ & $-6.2^{*}$ & -1.8 & $-4.0^{*}$ & -0.6 & 10.6 & 2.1 \\
\hline \multicolumn{8}{|l|}{ Blacks } \\
\hline Maxilla & 6.6 & 4.6 & 1.3 & -2.1 & 0.1 & 2.8 & - \\
\hline Mandible & -1.8 & -0.4 & 3.2 & 2.3 & 8.1 & 12.2 & 1.2 \\
\hline
\end{tabular}

${ }^{1}$ Males are predicted to show fewer "canine early" sequences; i.e., a negative sign is expected for these differences. * Sexes significantly different at $P<.05$ by chi-squared test; all sample sizes as in Figure 1.

TABLE 3. Population differences in frequencies of polymorphic sequences

\begin{tabular}{|c|c|c|c|c|c|c|c|}
\hline \multirow{3}{*}{$\begin{array}{l}\text { Dental } \\
\text { arch }\end{array}$} & \multicolumn{7}{|c|}{ Population difference in percent (white minus black) } \\
\hline & \multicolumn{3}{|c|}{ Canine sequences } & \multicolumn{4}{|c|}{ Molar sequences ${ }^{1}$} \\
\hline & CP1 & $\mathrm{CP} 2$ & CM2 & P1M2 & P2M2 & I1 M1 & I2M1 \\
\hline \multicolumn{8}{|l|}{ Males } \\
\hline Maxilla & $-9.2^{*}$ & $-23.8^{*}$ & 0.8 & $6.1^{*}$ & $8.0^{*}$ & $-7.1 *$ & - \\
\hline Mandible & 1.1 & -0.6 & $5.6^{*}$ & 1.0 & -3.2 & 3.9 & -4.7 \\
\hline \multicolumn{8}{|l|}{ Females } \\
\hline Maxilla & 6.9 & 4.6 & $7.7^{*}$ & $3.2 *$ & 4.3 & 0.6 & - \\
\hline Mandible & 10.7 & 5.2 & $10.7 *$ & $7.3^{*}$ & 5.6 & 5.5 & $-5.6^{*}$ \\
\hline
\end{tabular}

'Whites are predicted to show more "molar late" sequences; i.e., a positive sign is expected for these differences.

*Populations significantly different at $P<.05$ by chi-squared test; all sample sizes as in Figure 1. 
additionally indicating that it is white males that tend to stand out from other groups.

\section{Mandibular precedence}

This term refers to the tendency for mandibular teeth to precede maxillary teeth in development (see Israel et al., 1967; Burdi et al., 1975; Garn and Smith, 1980c). Table 4 gives the percent of children with mandibular tooth erupted and maxillary opponent unerupted, and thus frequencies for $\mathrm{I}_{1} \mathbf{I}^{1}, \mathrm{I}_{2} \mathrm{I}^{2}$, etc. It should be noted that emergence of some pairs of opponent teeth occurs in brief time intervals, and sample size is accordingly low for some opponent sequences. For example, in black males 133 children allowed discrimination of $M_{1} I_{1}$ vs. $I_{1} M_{1}$; only 67 cases remain to differentiate emergence of $M_{1}$ relative to $M^{1}$. It is generally true that the mandible is ahead of the maxilla in emergence, but a clear distance gradient can also be seen in jaw precedence. Anterior teeth have strong mandibular precedence, generally $>90 \%$. Maximum at I1, mandibular precedence decreases steadily to a minimum at P1 or P2 in all groups and then rises again at the distal arch for M1 and M2. The simplest gradient appears when teeth are ordered in space rather than time. The sharpest change in gradient occurs between $\mathrm{C}$ and $\mathrm{P} 1$ where mandibular precedence drops from ca. 80 to ca. $45 \%$. Premolars actually tend to show maxillary precedence as the more common condition. These findings are similar to those reported for Quechua and Pima Indians (Israel et al., 1967). In terms of population/sex comparisons we see much the same result as for within-arch polymorphisms. Here the overall pattern of results is shared and race/sex differences are incremental. White males tend to stand out from other groups by showing particularly low frequencies for the sequences $\mathrm{P}_{1} \mathrm{P}^{1}, \mathrm{P}_{2} \mathrm{P}^{2}$, and $\mathrm{M}_{1} \mathrm{M}^{1}$.

\section{DISCUSSION \\ Occlusion}

Eruption sequence polymorphisms in humans appear at high enough frequencies that the "most common" complete sequence characterizes a minority of children. It has been estimated that only a quarter of children share any one most common eruption sequence involving a single arch (Knott and Meredith, 1966; Savara and Steen, 1978). Thus, variation from the modal sequence is the rule.

The substantial number and level of sequence polymorphisms presents a puzzle for understanding the establishment of occlusion. Here it is relevant that the standard Angle classification is based on the relative position of upper and lower first molars (Angle, 1899). Thus, it is reasonable that Angle classification seems to be most strongly related to sequences involving these same teeth. Anderson and Popovich (1981) found that " $M{ }_{1}$ early" sequences, $M_{1} I_{1}$ or $M_{1} M^{1}$, showed the highest number of class I (normal) occlusions (best results obtained for children showing both these sequences). This effect may spill over to eruption of second molars, where "early $\mathrm{M}_{2}$ " sequences also appear to be more frequent in class I compared to class II occlusion (Lo and Moyers, 1953; Anderson and Popovich, 1981). Too few cases of class III have been seen in any study to permit a conclusion on any relationship to eruption sequence. It remains possible that other eruption sequences have consequences for occlusal relations that are not well reflected in Angle classification.

We might conclude from the high number and magnitude of sequence polymorphisms that the dentition is remarkably flexible in establishing a workable occlusion whatever

TABLE 4. Percent of children erupting mandibular before maxillary opponent out of cases allowing discrimination of sequence

\begin{tabular}{|c|c|c|c|c|c|c|c|c|}
\hline \multirow[b]{4}{*}{ Tooth } & \multicolumn{8}{|c|}{ Percent mandibular precedence } \\
\hline & \multicolumn{4}{|c|}{ White } & \multicolumn{4}{|c|}{ Black } \\
\hline & \multicolumn{2}{|c|}{ Male } & \multicolumn{2}{|c|}{ Female } & \multicolumn{2}{|c|}{ Male } & \multicolumn{2}{|c|}{ Female } \\
\hline & $(\mathrm{N})$ & $\%$ & (N) & $\%$ & (N) & $\%$ & (N) & $\%$ \\
\hline I1 & (284) & 94 & $(225)$ & 92 & $(158)$ & 91 & $(148)$ & 95 \\
\hline $\mathrm{I} 2$ & (314) & $94 \dagger$ & $(265)$ & 91 & $(208)$ & $87 \dagger$ & $(205)$ & 92 \\
\hline $\mathrm{C}$ & $(272)$ & $83^{\dagger}$ & $(274)$ & 84 & (154) & $73^{*}+$ & $(176)$ & $85 *$ \\
\hline P1 & (233) & $40^{*}$ & (196) & $54 *$ & $(117)$ & 44 & $(124)$ & 47 \\
\hline $\mathrm{P} 2$ & $(241)$ & $34^{*}, \dagger$ & $(225)$ & $48^{*}$ & (135) & $53^{\dagger}$ & (142) & 48 \\
\hline M1 & (121) & $50 *$ & $(97)$ & $71 *$ & $(67)$ & 60 & $(85)$ & 71 \\
\hline $\mathrm{M} 2$ & (222) & 71 & $(208)$ & 75 & (158) & 67 & (152) & 75 \\
\hline
\end{tabular}

* Sexes significantly different at $P<.05$ by chi-squared test, both sexes marked for clarity.

$\dagger$ Populations significantly different at $P<.05$ by chi-squared test, both groups marked. 


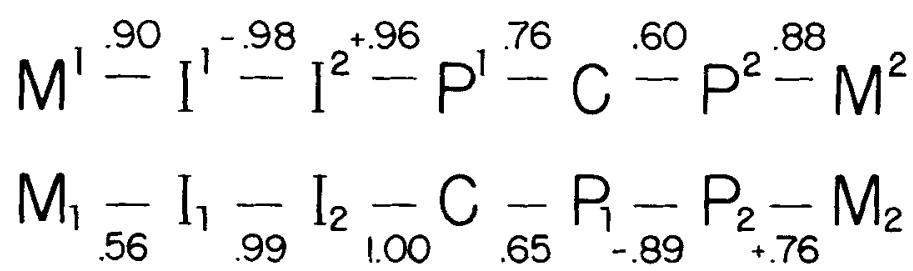

Fig. 2. Modal tooth emergence sequence from Ten State data accompanied by the frequency each two-tooth sequence is actually observed. The simple average of the four race/sex groups is given to illustrate a general pattern. Frequencies probably affected slightly by agenesis are marked to show direction they should be adjusted, +

the sequence. Yet it is clear that constraints are operating; variation is far from random across all tooth positions, even within eruption phases I and II (see Fig. 2). High variability occurs at some locations, but several positions show consistency or near uniformity of sequence.

\section{Dental development}

Eruption sequence polymorphisms are best understood in relation to the overall timing of tooth eruption. A cumulative frequency chart of age of tooth emergence for Ten State white females (Fig. 3) illustrates the "batching" of teeth into two major groups as noted in early studies of eruption. A representation of relative timing is achieved by using a $\log$ arithmic scale for age, stabilizing the variance of later-erupting teeth so that the distance between curves better represents the likelihood of sequence reversal (a standard scale requires that both distance and slope of curves be taken into account). Tooth eruption is clearly separated into phases I and II, with subgroups visible within each. The three most polymorphic mandibular sequences are reflected in the tight spacing of curves for $\mathrm{M} 1$ and $\mathrm{I} 1, \mathrm{C}$ and $\mathrm{P} 1$, and $\mathrm{P} 2$ and $\mathrm{M} 2$, respectively. Seen on this proportional scale, $\mathrm{C}$ and $\mathrm{P}_{1}$ reversals are nearly as likely as those of $\mathrm{M}_{1}$ and $\mathrm{I}_{1}$.

Knowledge about the timing of tooth eruption gives a general idea of sequence polymorphisms that are possible. Yet it is demonstrable that observed sequence variants occur at far lower rates than expected if sequences reversals are merely the result of overlapping independent frequency distributions. One can compute the expected frequency of sequence reversals under the assumption of independence from data in Figure $3 .^{1}$ Given independence, for these white females we expect the major sequence or - . Note that variation from the modal sequence is unevenly distributed. Greatest uniformity surrounds emergence of 12 , which rarely reverses with teeth in either phase I (M1, I1) or II (C, P1, P2, M2). Other sequences that are fairly consistent include $\mathrm{M}^{1} \mathrm{I}^{1}, \mathrm{P}^{2} \mathrm{M}^{2}$ and $\mathrm{P}_{1} \mathrm{P}_{2}$.

variant $\mathrm{I}_{1} \mathrm{M}_{1}$ at $.46, \mathrm{P}_{1} \mathrm{C}$ at .40 , and $\mathrm{P}_{2} \mathrm{M}_{2}$ at .33. Observed values are less, considerably so for the latter sequences: $.41, .27$, and .23 , respectively (of ten comparisons computed, all observed frequencies are less than expected values, significantly different from chance at $P<.05$ by sign test). The resolution of this discrepancy is that teeth are not independent in developmental timing and that correlation acts to reduce sequence variability (Clements et al., 1953; Garn and Lewis, 1963; Adler and Polczer, 1964). We know from longitudinal studies that correlations for emergence timing of teeth within a quadrant generally range from $r=.4$ to $r=.8$ (Knott and Meredith, 1966; Kent et al., 1978; Savara and Steen, 1978; Garn and Smith, 1980a). Of particular interest, teeth are most closely correlated with nearest neighbors in space rather than time, with correlations tending to decline as the number of intervening teeth increases (Garn and Smith, 1980a). Thus, $M_{1}$ and $I_{1}$, erupting at about the same time, are moderately correlated at $\mathrm{r}=.56$ (based on a longitudinal study of approximately 100 children as summarized in Garn and Smith, 1980a). The first molar is more closely related to the second molar $(r=.70)$, a tooth emerging some 6 years later. Similarly for other mandibular teeth, I1 development is tied to $\mathrm{I} 2(\mathrm{r}=.66), \mathrm{I} 2$ to $\mathrm{C}(\mathrm{r}=.70), \mathrm{C}$ to $\mathrm{P} 1$ $(r=.77)$, and $\mathrm{P} 1$ to $\mathrm{P} 2(\mathrm{r}=.77)$, forming a highly integrated system. Correlation of physically adjacent teeth helps explain why reversals of adjacent $C$ and $P_{1}$ are greatly

${ }^{1}$ Probabilities are obtained from a cumulative frequency graph of teeth erupted at the midpoint in age between the median ages of eruption for each tooth (using untransformed data). Under the assumption of independence, expected frequency for the sequence "IM" is obtained by the following: Let Ie = probability (I erupted), $I u=$ probability (I unerupted), $M e=$ probability (M erupted), $M u=$ probability (M unerupted), then probability (sequence $\mathrm{IM})=I e M u(I e M u+I u M e)$. For a similar analysis see Adler and Polczer (1964). 


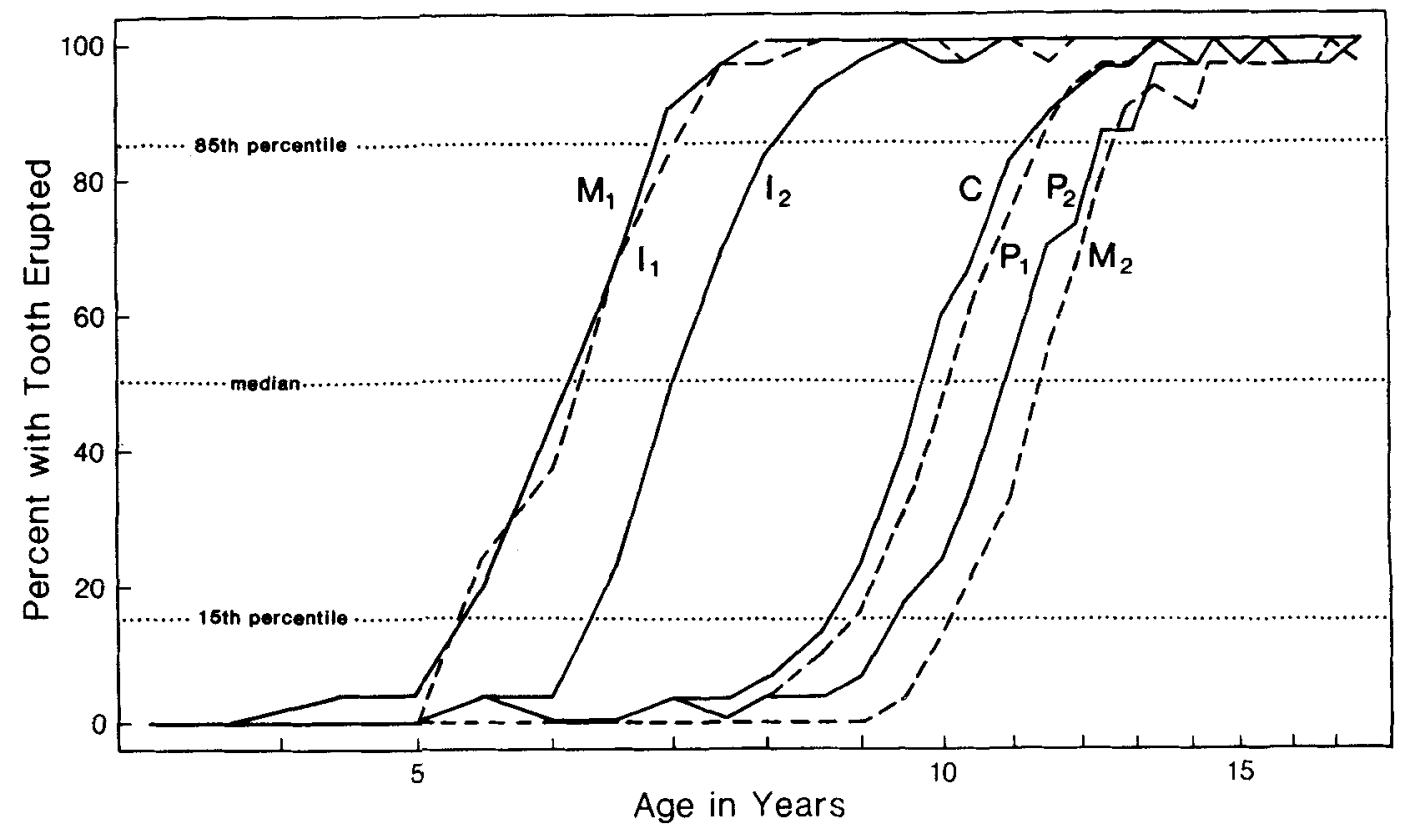

Fig. 3. Cumulative frequency graph for mandibular tooth emergence of 2,995 Ten State white females, fairly evenly distributed over 29 age intervals covering ages 3.25 to 17.5 years. Percent of cases with tooth erupted in each half-year interval is plotted against the midpoint of age interval (age 3.5 includes ages 3.25 to 3.749 , etc.). The logarithmic age scale adjusts for increasing vari-

lessened over those of distant $I_{1}$ and $M_{1}$ (and why $M_{1}$ may reverse with either $I_{1}$ or $I_{2}$ although $\mathrm{I}_{1}$ and $\mathrm{I}_{2}$ rarely reverse with each other).

Correlated development of adjacent teeth additionally explains why certain eruption sequences are associated. A general phenomenon of "molars late" explains the association of $\mathrm{I}_{1} \mathrm{M}_{1}$ with $\mathrm{P}_{2} \mathrm{M}_{2}$ found in longitudinal studies (Anderson and Popovich, 1981). Upper and lower opponents correlate in eruption time at an average of $r=.74$ (Garn and Smith, 1980a), a level that predicts multiple associations of maxillary and mandibular eruption sequences. Ten State children, for example, with the rarer $\mathbf{M}^{2} \mathbf{P}^{2}$ sequence in the maxilla are five to 12 times more likely to show this sequence also in the mandible than are other children (Garn and Smith, 1980b).

\section{Comparative odontology}

It should be noted that females erupt teeth earlier than males, a result common to all known populations (see tabulations in Dahlberg and Menegaz-Bock, 1958; Jaswal, 1983).

ance of later-erupting teeth, equalizing slopes of curves. Only with this scale is the distance between curves a direct indicator of the relative closeness of eruption of teeth. Note the separation in time between phase I and phase II teeth. The three major mandibular polymorphisms are reflected in close spacing of curves for M1 and $I 1, P 1$ and $C$, and $P 2$ and $M 2$.

Thus sexual dimorphism in tooth eruption is a question of degree rather than presence or absence. Sequence dimorphism should indicate a further differential delay of tooth eruption in males.

In Ten State data, whites show a strong canine sequence dimorphism that is not replicated in blacks. Related studies tend to support both findings. For most human groups we know only the dominant sequence (that present at $>50 \%$ ) from the order of mean ages of tooth emergence. Fourteen population studies reviewed in Jaswal (1983) and 15 older studies in Adler and Godeny (1952) show some worldwide similarities. The dimorphic sanine sequences $\mathrm{P}^{2} \mathrm{C}$ (male) and $\mathrm{CP}^{2}$ (female) observed in Ten State whites also occur in other populations. Overall, $\mathrm{P}^{2} \mathrm{C}$ is reported as the male sequence in 21 of 28 populations (one tie), whereas females tend to $\mathrm{CP}^{2}$ (14 of 24 cases, five ties). However, distribution of these sequences is not random with respect to group. These sex-specific sequences appear in about half the 14 European or European-derived groups compared with one-fifth of the 15 other groups sur- 
veyed by Adler and Godeny (1952) and Jaswal (1983). Of particular interest, none of the three studies of African or African-derived groups reports these sex specific sequences; instead, both males and females show $\mathrm{CP}^{2}$ as found in Ten State blacks (original sources: Suk, 1919; Steggerda and Hill, 1942; Houpt et al., 1967). Therefore, the appearance of canine sequence dimorphism in whites but not blacks observed in the present study may be correct. Unfortunately, median sequences are insensitive measures and intra-arch sequences are only one aspect of dimorphism. Dimorphism may also exist in the more subtle and complex sequence of all six premolar and canine teeth in the two arches (Adler and Godeny, 1952; Jaswal, 1983).

Dimorphism is not generally discussed for the sequence $I_{1} M_{1}$. Ten State black and white males show substantial increases $(>10 \%)$ in the frequency of $I_{1} M_{1}$ (and $M^{1} M_{1}$ ) compared to females. Knott and Meredith's (1966) study of Iowa children showed the same result. Of $\mathrm{N}=56$ males, $64 \%$ showed $\mathrm{I}_{1} \mathrm{M}_{1}$ as opposed to only $46 \%$ of $\mathrm{N}=50$ females. Data of Savara and Steen (1978), although organized in a manner that prevents explicit comparison, suggest the same finding. The sequence $I_{1} M_{1}$ may be both sexually dimorphic and different between populations (see below). This finding could have clinical significance since $I_{1} M_{1}$ and $M^{1} M_{1}$ are the sequences so far indicated to be least favorable for Angle classification of occlusion (Anderson and Popovich, 1981).

In overall pattern of sequence polymorphism (location, level, and number), the four race/sex groups are far more similar than different; all, for example, share the same five most polymorphic sequences at similar levels. However, some population differences are evident in molar sequences, whites showing more "molar late" sequences such as $\mathrm{I}_{1} \mathrm{M}_{1}, \mathrm{CM}_{2}, \mathrm{P}^{2} \mathrm{M}^{2}$, and $\mathrm{P}_{2} \mathrm{M}_{2}$. The latter sequence has received the most attention in the literature. European-derived populations tend to have lower frequencies of $\mathrm{M}_{2} \mathrm{P}_{2}$ than other human groups: compare $48 \%$ in Pima Indians (Koski and Garn, 1957) and 63\% in Australian aborigines (Barrett et al, 1964) with the value of approximately $24 \%$ in Ten State whites. This value may represent a good average estimate for $\mathrm{M}_{2} \mathrm{P}_{2}$ in Europeanderived populations, as other studies of these groups report its occurrence between 13 and $36 \%$ (see Garn and Lewis, 1963; Knott and Meredith, 1966). ${ }^{2}$ Ten State blacks, however, are substantially closer to whites than the Australian or American Indian groups above, with frequencies no greater than $30 \%$.

The sequences $M_{1} I_{1}$ and $M_{2} P_{2}$ are of particular interest taken together. These sequences might be expected to be related on a population level, as they are in individuals (Anderson and Popovich, 1981). Thus, the variants $\mathrm{I}_{1} \mathrm{M}_{1}$ (a molar late sequence) and $\mathrm{M}_{2} \mathrm{P}_{2}$ (a molar early sequence) should be inversely related: a population might be high in one, but not both, of these variant sequences. Thus, Ten State whites have high frequencies of $\mathrm{I}_{1} \mathrm{M}_{1}$ (ca. $45 \%$ ) but only moderate frequencies of $\mathrm{M}_{2} \mathrm{P}_{2}$ (ca. $24 \%$ ). In contrast, Australian aborigines (Barrett et al., 1964) reportedly show $I_{1} M_{1}$ at only $12 \%$, with $\mathrm{M}_{2} \mathrm{P}_{2}$ dominant at $63 \%$. Other groups with early molar eruption, such as the Pima Indians (Dahlberg and Menegaz-Bock, 1958), would be expected to show low levels of $I_{1} M_{1}$.

\section{Evolution}

Early work on the evolution of eruption sequences included methodological problems (e.g., Drennan, 1932; Weidenreich, 1937; Senyurek, 1955), particularly in the definition of eruption (Garn et al., 1956, 1957; Koski and Garn, 1957). Wallace (1977) ameliorated the problem of comparing the living with the dead by using presence of wear striations to confirm gingival emergence in fossil specimens. Still, poor available comparative data hampered phylogenetic study. Wallace (1977) thought that M2I2 was a real possibility in humans (jaw unspecified)-one sequence we find very unlikely. Lumping of maxillary and mandibular sequences further obscured comparisons in his study. Similarly, Nissen and Riesen (1964:293) list $\mathrm{P}_{2} \mathrm{C}$ as the usual sequence in modern whites; yet $\mathrm{P}_{2} \mathrm{C}$ is present in less than $15 \%$ of Ten State whites. Some difficulties may arise from a confusion of maxillary and mandibular sequences (maxillary $\mathrm{P}^{2} \mathrm{C}$ is fairly common at ca. $40 \%$ ) others from an equation of "may occur" with "commonly occurs." In contrast to these examples where a rare sequence is said to be common, the common sequence $\mathrm{I}_{1} \mathrm{M}_{1}$ is often

\footnotetext{
${ }^{2}$ Caries may be responsible for two studies of British children reporting $\mathrm{M}_{2} \mathrm{P}_{2}$ as the dominant sequence (Clements et al., 1953 Miller et al., 1965) since early extraction of $\mathrm{dm} 2$ can delay emergence of P2 (Posen, 1965; Ronnerman, 1977; see also Adler, 1963). These postwar British children were drawn from a population with one of the highest caries rates attained in the world at any time in history (James and Parfitt, 1957; Hardwick, 1960). Caries rates have subsequently dropped worldwide (DePaola et al., 1982; Anderson et al., 1982), so this should be a less impor. tant factor in more recent studies.
} 
said to be rare (Wallace, 1977; Jaswal, 1983). Adler and Godeny (1952) also said this, but admitted that their sample of very young children was inadequate in both number and age range.

The substantial number of high-level variants in human eruption sequence makes it unlikely that hominid fossils can be shown to be categorically different from Homo sapiens. However, the timing and correlation of the human dentition makes some sequences truly rare. Many new fossils have been recovered in the last 20 years. It is (or will soon be) possible to compare fossil samples to frequency distributions of eruption sequences in modern humans. The new early $H$. erectus juvenile, WT 15000, is reported to show $\mathrm{M}^{2} \mathrm{C}$, ". . a known human condition ..." (Brown et al., 1985:789). For comparability of data, this sequence must still be confirmed by presence of wear on $\mathrm{M}^{2}$ (the deciduous upper canine was apparently still in place). Wallace's (1977) work did verify a gingival sequence of $\mathrm{M}_{2} \mathrm{C}$ on the juvenile $A$. africanus mandible MLD 2, and no early hominid fossils are known to differ. If we ask whether these fossils are more likely drawn from a pongidlike or humanlike frequency distribution of sequences, the present answer is a pongid distribution. The chance of drawing two individuals like this in known humans is $1 \%$ or less; in pongids it is $100 \%$ as far as we know (see Schultz, 1940; 1941). The point of this example is twofold: (1) simply organized basic data on humans makes it possible to compare probabilities, rather than insist on (unlikely) categorical differences, and (2) this approach offers some escape from the stalemate brought about by regarding "humanlike" as a null hypothesis to be disproved-hardly possible when fossils are rare and human data are poor. At the very least, these comprehensive descriptive data on modern humans point out which sequences may be worth investigating and which are not.

One fairly substantial problem remains for phylogenetic study of eruption within the Hominoidea. Available data on pongid eruption sequences were collected on skeletal samples, defining eruption by height of the tooth relative to the alveolus (Schultz, 1935, 1940; Clements and Zuckerman, 1953). This work gives us a general outline of sequence; M1 I1 I2 M2 [P1 P2] C M3 appears to characterize chimpanzees and gorillas, with M1 I1 [I2 M2] [P1 P2] C M3 reported for the orangutan (Schultz, 1941). We add brackets to set off variants reported at $>20 \%$ by these authors; however, the level of variation is probably the most sensitive to different eruption criteria. Small samples of living chimpanzees seen by Nissen and Riesen (1964) suggest the possibility of more extensive polymorphism, possibly M1 I1 [I2 M2 P1 P2] C M3, but their data are not organized in a manner to make this clear. Pongid eruption sequences must be restudied (using wear as

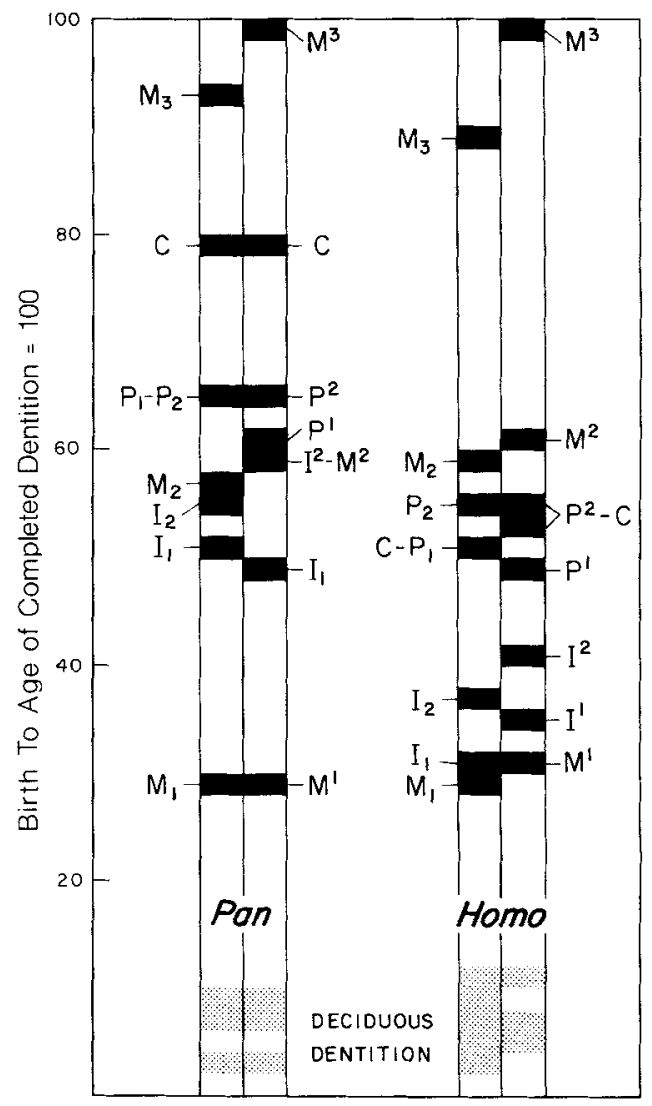

RELATIVE AGE OF ERUPTION

Fig. 4. Relative age of tooth eruption in chimpanzees and humans, modified from Schultz (1935). Mandibular teeth at left and maxillary teeth at right in paired columns for each genus. As Schultz pointed out, the greatest space or rest phase in chimpanzee tooth eruption occurs between M1 and later teeth. Humans, in contrast, closely associate M1 and incisor eruption. Chimpanzees have only one closely timed group of teeth, the central set of $\mathrm{I} 1, \mathrm{I} 2, \mathrm{M} 2, \mathrm{P} 1$ and $\mathrm{P} 2$. Common variant sequences predictable from this timing include $\mathrm{M} 212$, P2P1, and even perhaps M2I1-sequences extremely rare in humans. Human eruption data from Hurme (1949) and Lunt and Law (1964); chimpanzee data from Nissen and Riesen (1945, 1964). 
the criterion of gingival emergence for skeletal samples or gingival emergence on living animals) if we wish to compare pongids with humans. Even if pongids turn out to have several sequence polymorphisms, these should appear at locations that are entirely distinct from humans (Fig. 4).

It is true that judging a sequence of eruption reduces developmental information in fossils to a minimum (erupted/unerupted)always a problem with small samples of juvenile fossils. Study of tooth formation can help, since this approach makes use of more information from a single jaw (Moorrees et al., 1963; Dean and Wood, 1981; Smith, 1986). It seems likely that we can profit from phylogenetic comparisons of dental development, including eruption sequences, as long as care is taken to insure comparability of data.

\section{CONCLUSIONS}

Eruption sequence polymorphisms studied in this large sample of American children show a definite pattern of location, number, and level. (1) Polymorphic sequences occur within and not between teeth in eruption phases I and II. (2) At least five variant sequences occur at $\geqslant 20 \%$. (3) More variants are found in the mandible than in the maxilla. (4) Sexual dimorphism appears in canine sequences (whites only) and in the sequence $M_{1} I_{1} I_{1} M_{1}$ (both populations). Males tend to show higher frequencies of sequences with late canine emergence and higher frequencies of $\mathrm{I}_{1} \mathrm{M}_{1}$ than females. (5) Whites tend to show an excess of "molar late" sequences compared to blacks. The higher degree of sexual dimorphism in eruption sequence observed in whites can also be described as a population difference.

Close timing of two major groups of erupting teeth may be the most important factor in explaining the magnitude of human erup. tion sequence variation. However, strongly correlated development of physically adjacent teeth acts to dampen or limit sequence variability, preventing many polymorphisms from reaching levels of 40 or $50 \%$ that would occur if teeth developed independently. Although the human dentition must be flexible to some degree in establishment of occlusion given observed sequence variations, it seems clear that constraints are operating.

Although eruption sequences are polymorphic in the literal sense of the word, "more than one form," control mechanisms are not likely to be single genes specific to single sequences. Genes that modify development of an entire morphologic series of teeth probably bring about whole sets of correlated sequences. Population differences and evolutionary change may be best analyzed in terms of relative change in timing of the incisor, canine, premolar, and molar fields. Thus, genes that bring about "molar late" sequences (e.g., $\mathrm{I}_{1} \mathrm{M}_{1}$ and $\mathrm{P}_{2} \mathrm{M}_{2}$ ) may also predispose to later calcification, smaller size, simpler morphology, or agenesis of teeth in the molar series (Garn et al., 1963; Anderson and Popovich, 1981; Lavelle et al., 1970)conceivably extending to differences in occlusal relations as well.

Timing and sequence of tooth eruption should be related in a broad sense to life span, craniofacial growth, establishment of occlusion, maturation of muscles of mastication, sexual maturation, and demands of use. We have some knowledge of the relationship of these variables in primates (Schultz, 1935, 1940, 1941, 1960; Baume and Becks, 1950; Hurme and Van Wagenen, 1956; Swindler and Gavin, 1962; Nissen and Riesen, 1964; Gavin, 1967; Tappen and Severson, 1971; Shigehara, 1980; Dean and Wood, 1981; Fleagle and Schaffler, 1982; Swindler, 1985), but further study is needed of both living and fossil primates. The human dentition may be unusual in its pattern of development, particularly in the distinct grouping of teeth into two sets in eruption, yet it remains to be demonstrated whether humans are more variable than other primates in eruption sequence.

As a final note, we might ask whether it is possible to state a "human" eruption sequence. Complete sequences could easily be written with an attached figure for level of polymorphism. Combining Schultz's used of brackets to indicate variability with $a \geqslant 20 \%$ threshold shows the major human polymorphisms and results in a sequence that would probably apply to most groups: M1 I1 I2 [P1 C P2] M2 in the maxilla and [M1 I1] I2 [C $\mathrm{P} 1]$ [P2 M2] in the mandible.

\section{ACKNOWLEDGMENTS}

We thank D.L. Anderson, C.L. Brace, M.C. Dean, P.D. Gingerich, and anonymous reviewers for comments on the manuscript. This research was supported by National Science Foundation grant BNS 8406421 to B.H.S. and National Institute of Dental Research grant DE 03610 to S.M.G. 


\section{LITERATURE CITED}

Adler, $\mathbf{P}$ (1963) Effect of some environmental factors on sequence of permanent tooth eruption. J. Dent. Res. 42:605-616.

Adler, P, and Godeny, E (1952) Studies on the eruption of the permanent teeth. II. The sequence of eruption. Acta Genet. (Basel) 3:30-49.

Adler, P, and Polczer, MG (1964) Phases in the second period of permanent tooth eruption. Acta Genet. (Basel) 14:338-350.

Anderson, DL, and Popovich, F (1981) Association of relatively delayed emergence of mandibular molars with molar reduction and molar position. Am. J. Phys. Anthropol. 54:369-376.

Anderson, RJ, Bradnock, G, Beal, JF, and James, PMC (1982) The reduction of dental caries prevalence in English schoolchildren. J. Dent. Res. 61:(Sp Iss):13111316.

Angle, EH (1899) Classification of malocclusion. Dent. Cosmos 1899:248-264.

Barrett, MJ, Brown, T, and Cellier, KM (1964) Tooth eruption sequence in a tribe of central Australian aborigines. Am. J. Phys. Anthropol. 22:79-89.

Baume, LJ, and Becks, H (1950) The development of the dentition of Macaca mulatta: Its difference from the human pattern. Am. J. Orthod. 36:723-748.

Brown, F, Harris, J, Leakey, R, and Walker, A (1985) Early Homo erectus skeleton from west Lake Turkana, Kenya. Nature 316:788-792.

Burdi, AR, Garn, SM, and Superstine, JN (1975) Mandibular precedence in the prenatal development of four permanent teeth. Am. J. Phys. Anthropol. 43:363-366.

Clements, EMB, Davies-Thomas, E, and Pickett, KG (1953) Order of eruption of the permanent human dentition. Br. Med. J. 1:1425-1427.

Clements, EMB, and Zuckerman, S (1953) The order of eruption of the permanent teeth in the Hominoidea. Am. J. Phys. Anthropol. 11:313-337.

Dahlberg, AA, and Menegaz-Bock, RM (1958) Emergence of the permanent teeth in Pima Indian children. J. Dent. Res. 37:1123-1140.

Dart, RA (1948) The adolescent mandible of Australopithecus prometheus. Am. J. Phys. Anthropol. 6:391-411.

Dean, MC (1985) The eruption pattern of the permanent incisors and first permanent molars in Australopithecus (Paranthropus) robustus. Am. J. Phys. Anthropol. 67:251-257.

Dean, MC, and Wood, BA (1981) Developing pongid dentition and its use for ageing individual crania in comparative cross-sectional growth studies. Folia Primatol. (Basel) 36:111-127.

Debrot, A (1968) Eruption sequences in children of Curaçao, Netherlands Antilles. J. Dent. Res. 47:83-86.

DePaola, PF, Soparkar, PM, Tavares, M, Allukian, M, and Peterson, H (1982) A dental survey of Massachusetts schoolchildren. J. Dent. Res. 61:(Sp Iss):13561360.

Drennan, MR (1932) L'ordre d'éruption des dents permanentes chez les boschimans. L'Anthropologie 42: 491-495.

Fleagle, JG, and Schaffler, MB (1982) Development and eruption of the mandibular cheek teeth in Cebus albifrons. Folia Primatol. (Basel) 38:158-169.

Garn, SM, and Burdi, AR (1971) Prenatal ordering and postnatal sequence in dental development. J. Dent. Res. 50:1407-1414.

Garn, SM, and Koski, K (1957) Tooth eruption sequence in fossil and recent man. Nature 180:442-443.
Garn, SM, Koski, K, and Lewis, AB (1957) Problems in determining the tooth eruption sequence in fossil and modern man. Am. J. Phys. Anthropol. 15:313-331.

Garn, SM, and Lewis, AB (1963) Phylogenetic and intraspecific variations in tooth sequence polymorphisms In DR Brothwell (ed): Dental Anthropology. Oxford: Pergamon, pp. 53-73.

Garn, SM, Lewis, AB, and Shoemaker, DW (1956) The sequence of calcification of the mandibular molar and premolar teeth. J. Dent. Res. 35:555-561.

Garn, SM, Lewis, AB, Swindler, DR, and Kerewsky, RS (1967) Genetic control of sexual dimorphism in tooth size. J. Dent. Res. 46:963-972.

Garn, SM, Lewis, AB, and Vicinus, JH (1962) Third molar polymorphism and reduction in the number of other teeth. J. Dent. Res. 41:717.

Garn, SM, Lewis, AB, and Vicinus, JH (1963) Third molar polymorphism and its significance to dental genetics. J. Dent. Res. 42:257-276.

Garn, SM, Nagy, JM, Sandusky, ST, and Trowbridge, F (1973a) Economic impact on tooth emergence. Am. J. Phys. Anthropol. 39:233-238.

Garn, SM, Sandusky, ST, Miller, RL, and Nagy, JM (1972a) Developmental implications of dichotomous ossification sequences in the wrist region. Am. J. Phys. Anthropol. 37:111-116.

Garn, SM, Sandusky, ST, Nagy, JM, and 'Trowbridge, FL (1973h) Negro-Caucasoid differences in permanent tooth emergence at a constant income level. Arch. Oral Biol. 18:609-615.

Garn, SM, and Smith, BH (1980a) Developmental communalities in tooth emergence timing. J. Dent. Res. 59:1178.

Garn, SM, and Smith, BH (1980b) Eruption sequence similarities in the maxilla and mandible. J. Dent. Res. $59: 1534$

Garn, SM, and Smith, BH (1980c) A mandibular-maxillary precedence field in tooth emergence timing. J. Dent. Res. 59:1525.

Garn, SM, Wertheimer, F, Sandusky, ST, and McCann, MB (1972b) Advanced tooth emergence in Negro individuals. J. Dent. Res. 51:1506.

Gavin, JA (1967) Eruption of primate deciduous dentition: a comparative study. J. Dent. Res. 46:984-988.

Grahnen, H (1956) Hypodontia in the permanent dentition. Odont. Rev. [Suppl.]7(3):1-100.

Hardwick, $\pi(1960)$ The incidence and distribution of caries throughout the ages in relation to the Englishman's diet. Br. Dent. J. 108:9-17.

Houpt, ML, Adu-Aryees, S, and Grainger, RH (1967) Eruption times of permanent teeth in the Brong Ahafee region of Ghana. Am. J. Orthod. 53:95-99.

Hurme, VO (1949) Ranges of normalcy in the eruption of permanent teeth. J. Dent. Child. 16:11-15.

Hurme, VO (1957) Time and sequence of tooth eruption. J. Forensic Sci. 2:377--388.

Hurme, VO, and Van Wagenen, G (1956) Emergence of permanent first molars in the monkey (Macaca mulatta). Association with other growth phenomena. Yale J. Biol. Med. 28:538-567.

Israel, R, Dahlberg, AA, Garn, SM, and Kerewsky, R (1967) Relative eruption precedence of mandibular and maxillary teeth in two populations. J. Dent. Res. 47:456.

James, PMC, and Parfitt, GJ (1957) The dental conditions of London school children over a period of seven years. Br. Dent. J. 103:214-216.

Jaswal, S (1983) Age and sequence of permanent-tooth 
emergence among Khasis. Am. J. Phys. Anthropol 62:177-186.

Johnsen, DC (1977) Prevalence of delayed emergence as a result of local factors. J. Am. Dent. Assoc. 94:100 106.

Kent, RL, Reed, RB, and Moorrees, CFA (1978) Associations in emergence age among permanent teeth. Am. J. Phys. Anthropol. 48:131-142.

Knott, VB, and Meredith, HV (1966) Statistics on the eruption of the permanent dentition from serial data for North American white children. Angle Orthod. $36: 68-79$.

Koski, K, and Garn, SM (1957) Tooth eruption sequence in fossil and modern man. Am. J. Phys. Anthropol. 15:469-488.

Lavelle, CLB, Ashton, EH, and Flinn, RM (1970) Cusp pattern, tooth size and third molar agenesis in the human mandibular dentition. Arch. Oral Biol. 15:227237.

LeBot, P, and Salmon, D (1977) Congenital defects of the upper lateral incisors (ULI): condition and measurements of the other teeth, arch, head and face. Am. J. Phys. Anthropol. 46:231-244.

Lo, RT, and Moyers, RE (1953) Studies in the etiology and prevention of malocclusion. I. The sequence of eruption of the permanent dentition. Am. J. Orthod. $39: 460-467$.

Lunt, RC, and Law, DB (1974) A review of the chronology of eruption of deciduous teeth. J. Am. Dent. Assoc. 89:872-879.

Mayhall, JT, Belier, PL, and Mayhall, MF (1978) Canadian Eskimo permanent tooth emergence timing. Am. J. Phys. Anthropol. 49:211-216.

Miller, J, Hobson, P, and Gaskell, TJ (1965) A serial study of the chronology of exfoliation of deciduous teeth and exuption of permanent teeth. Arch. Oral Biol. 10:805-818.

Moorrees, CFA, Fanning, EA, and Hunt, EE (1963) Age variation of formation stages for ten permanent teeth. J. Dent. Res. 42:1490-1502.

Moss, ML, and Moss-Salentijn, L (1977) Analysis of developmental processes possibly related to human dental sexual dimorphism in permanent and deciduous canines. Am. J. Phys. Anthropol. 46:407-414.

Nissen, HW, and Rjesen, AH (1945) The deciduous dentition of chimpanzee. Growth 9:265-274.

Nissen, HW, and Riesen, AH (1964) The eruption of the permanent dentition of the chimpanzee. Am. J. Phys. Anthropol. 22:285-294.

Posen, AL (1965) The effect of premature loss of deciduous molars on premature eruption. Angle Orthod. 35:249-252.
Ronnerman, A (1977) The effect of early loss of primary molars on tooth eruption and space conditions. A longitudinal study. Acta Odont. Scand. 35:229-239.

Savara, BS, and Steen, JC (1978) Timing and sequence of eruption of permanent teeth in a longitudinal sample of children from Oregon. J. Am. Dent. Assoc. 97:209-214

Schour, I, and Massler, M (1941) The development of the human dentition. J. Am. Dent. Assoc. 28:1153-1160.

Schultz, AH (1935) Eruption and decay of the permanent teeth in primates. Am. J. Phys. Anthropol. 19:489-581.

Schultz, AH (1940) Growth and development of the chimpanzee. Carn. Pub. Wash. Contrib. Embryol. 28:1-63.

Schultz, AH (1941) Growth and development of the orang-utan. Carn. Pub. Wash. Contrib. Embryol. 29:59110

Schultz, AH (1960) Age changes in primates and their modification in man. In JM Tanner (ed): Human Growth. Oxford: Pergamon, pp. 1-20.

Senyurek, M (1955) A review of the order of eruption of the permanent teeth in fossil hominids. Turk Tarih Kurumu Bulletin 19:407-444.

Shigehara, N (1980) Epiphyseal union, tooth eruption, and sexual maturation in the common tree shrew, with reference to its systematic position. Primates 21:1-19.

Smith, BH (1986) Dental development in Australopithecus and early Homo. Nature 323:327-330.

Steggerda, M, and Hill, TJ (1942) Eruption time of teeth among whites, negroes, and Indians. Am. J. Orthod. 28:361-370.

Swindler, DR (1985) Nonhuman primate dental development and its relationship to human dental development. In ES Watts (ed): Nonhuman Primate Models for Human Growth and Development. New York: Alan R. Liss, pp. 67-94.

Swindler, DR, and Gavin, JA (1962) Calcification of the mandibular molars in rhesus monkeys. Arch. Oral Biol. 7:727-734

Suk, V (1919) Eruption and decay of permanent teeth in whites and negroes with comparative remarks on other races. Am. J. Phys. Anthropol. 2:351-388.

Tappen, NC, and Severson, A (1971) Sequence of eruption of permanent teeth and epiphyseal union in New World monkeys. Folia Primatol. (Basel) 15:243-312.

Wallace, JA (1977) Gingival eruption sequences of per manent teeth in early hominids. Am. J. Phys. Anthro pol. 46:483-494.

Weidenreich, F (1937) The dentition of Sinanthropus pekenensis: A comparative odontography of the hominids. Palaeon. Sinica 1:120-180. 